\title{
Intralesional Methotrexate for the Treatment of Keratoacanthoma: The Neapolitan Experience
}

\author{
Massimiliano Scalvenzi · Angela Patrì · Claudia Costa • \\ Matteo Megna · Maddalena Napolitano - Gabriella Fabbrocini • \\ Nicola Balato (D)
}

Received: December 8, 2018 / Published online: February 21, 2019

(C) The Author(s) 2019

\begin{abstract}
Introduction: Keratoacanthomas are cutaneous neoplasms known for their rapid growth and spontaneous regression over a long time period. Their treatment can be difficult because of the potentially large field size and number of lesions. Intralesional methotrexate constitutes an effective, nonsurgical treatment of keratoacanthomas, as proven by our experience.

Methods: We treated 11 elderly patients affected by keratoacanthoma with intralesional methotrexate. The injections were performed weekly, followed by $10 \mathrm{mg}$ of folic acid to be taken 24 h later.

Results: All our patients underwent complete resolution of the lesions after $4-8$ injections, without side effects.

Conclusion: Intralesional methotrexate seems to be an effective and safe nonoperative
\end{abstract}

Enhanced Digital Features To view enhanced digital features for this article go to https://doi.org/10.6084/ m9.figshare.7694504.

M. Scalvenzi · A. Patrì - C. Costa $\cdot$ M. Megna ·

G. Fabbrocini $\cdot$ N. Balato $(\bowtie)$

Department of Dermatology, University of Naples

Federico II, Naples, Italy

e-mail: balato@unina.it

M. Napolitano

Department of Medicine and Health Sciences

Vincenzo Tiberio, University of Molise,

Campobasso, Italy treatment modality for keratoacanthoma, especially when it arises in anatomic areas difficult to treat with surgery, in elderly debilitated patients, and in those refusing surgery.

Keywords: Keratoacanthoma; Methotrexate; Nonsurgical treatment

\section{INTRODUCTION}

Keratoacanthoma (KA) is a rapidly growing cutaneous neoplasm deriving from the hair follicle [1], currently considered an in situ squamous cell carcinoma [2, 3]. It usually occurs on sun-exposed sites in elderly people but may also develop in areas of trauma including burns, laser treatment, radiation, and surgical margins from excisional biopsies or skin grafting [4].

Surgical excision constitutes the treatment of choice for the majority of cases; nevertheless, several other treatment modalities have been reported, including systemic retinoids, intralesional and topical 5-fluorouracil, intralesional methotrexate (MTX), laser therapy, electrodesiccation and curettage, radiotherapy, and photodynamic therapy [5].

MTX is appropriate for rapidly growing tumors because it inhibits DNA synthesis in actively dividing cells. It is a folic acid analog that binds to the dihydrofolate reductase, blocking the formation of tetrahydrofolate and preventing the synthesis of the purine 
nucleotide thymidine [6]. Intralesional MTX is a potential alternative to surgical treatment of KAs as a less invasive and less costly treatment modality with decreased morbidity [4].

Thus, to evaluate the efficacy of intralesional MTX in the treatment of KA, patients' data from the the Department of Dermatology, University of Naples Federico II, from January 2017 to October 2018 were retrospectively analyzed. We identified 11 patients with KA treated with intralesional injections of MTX. Informed consent was obtained from all individual participants for being included in the study.

\section{CASE SERIES}

At our institution, a pre-treatment biopsy was performed, which confirmed the diagnosis of KA in all 11 cases ( 5 male, 6 female). The average age was 66.2 years. All patients were affected with a solitary KA except for one $(9.1 \%)$, presenting with three tumors. KAs were located on the face $(6,54.5 \%)$, ears $(2,18.2 \%)$, hands $(2$, $18.2 \%)$, and trunk $(3,9.1 \%)$. The tumors ranged in diameter from 0.6 to $3.5 \mathrm{~cm}$ (mean, $2.1 \mathrm{~cm}$ ). The dosage of methotrexate was chosen according to the tumoral size: $20 \mathrm{mg}$ for KAs measuring $\leq 2 \mathrm{~cm}$ in diameter (6 patients) and $25 \mathrm{mg}$ for those measuring $>2 \mathrm{~cm}$ (5 patients). The injections were performed weekly at the base of the tumor using a 24-gage needle, followed by $10 \mathrm{mg}$ folic acid to be taken $24 \mathrm{~h}$ later.

To achieve tumor resolution, four to eight injections (mean 5.3) were required. A complete blood cell count as well as a dosage of transaminases at baseline and during treatment was performed. All our patients underwent complete resolution, with only a minimal atrophic cicatricial outcome and without any systemic side effects (Fig. 1). A quicker response to treatment was obtained in cases of KAs measuring $\leq 2 \mathrm{~cm}$ in diameter. No recurrence was found at the 6-9-month follow-up.

\section{DISCUSSION}

Because KA can regress spontaneously, some authorities claim that it does not require treatment [7]. However, KA may take a long time to involute spontaneously and may continue to enlarge during this time, resulting in the destruction of the involved tissues. Multiple treatment alternatives exist for KAs, with the standard of care for large or high-risk KAs being excisional surgery [8].

Intralesional chemotherapy for non-melanoma skin cancer has existed for more than 5 decades. Nevertheless, it is used so infrequently that recent consensus guidelines for the treatment of squamous cell carcinoma, as well as basal cell carcinoma, do not include intralesional chemotherapy [9]. Barriers to its use include the absence of therapeutic guidelines, off-label utilization of these agents, a relatively small number of patients treated, and a lack of large, well-designed trials with long-term follow-up [9].

Nonetheless, nonoperative approaches may need to be considered in well-selected patients when a poor cosmesis and loss of function are expected from the surgery or they will not or cannot undergo surgery, e.g., elderly patients or those with comorbidities. In these cases, intralesional MTX, as an example of a nonsurgical treatment modality, offers a less invasive treatment option with acceptable cosmetic results. On the other hand, this approach could constitute a neoadjuvant therapy to reduce tumor size while waiting for surgery to reduce surgical invasiveness.

For our patients, we opted for intralesional MTX because of both its effectiveness for solitary and multiple KAs [4] and reasonably decreased risk of morbidity compared with surgical excision for delicate regions such as the face, ears, and hands in elderly patients. This simple procedure appears to be efficacious, painless, and safe, with no significant systemic adverse events.

However, treatment with MTX would not have been attempted if there had been any doubt that the lesions were not the well-differentiated KA type. Moreover, a complete blood cell count as well as a dosage of transaminases at baseline and during treatment should be considered [10]. Even if we had used such dosages until the end of treatment, it could have been interesting to monitor the occurrence of 

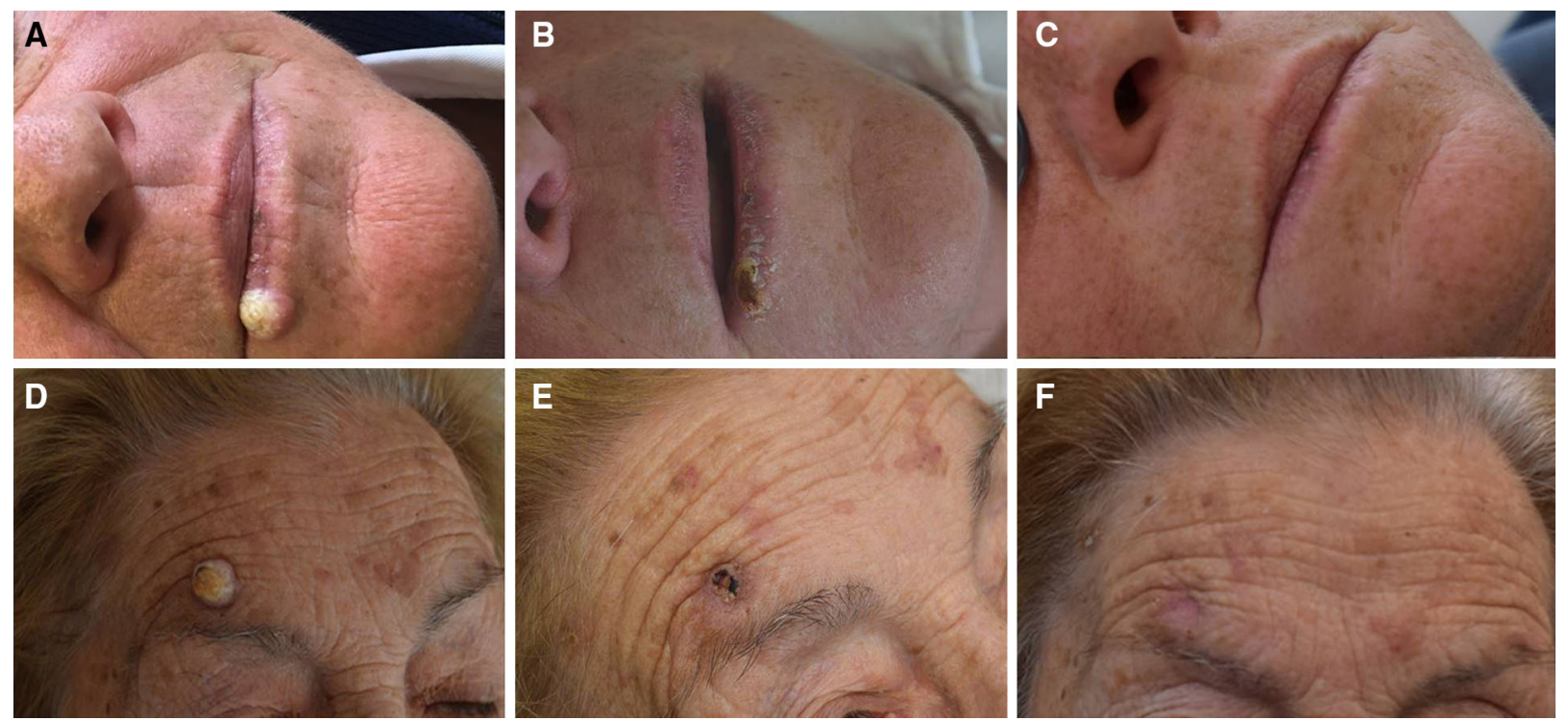

Fig. 1 Treatment course summary for KA in two patients. a Appearance of the tumor on the lower lip prior to treatment. b Appearance of the tumor 2 weeks after starting treatment. c Appearance of the tumor 6 weeks after starting treatment (total of 6 methotrexate injections), with minimal atrophic cicatricial outcomes.

cytopenia and alterations of liver enzymes also during the follow-up, especially in elderly patients or in case of concomitant diseases.

\section{CONCLUSIONS}

We hope that our evidence, together with other literature reports $[1,2,4,5,7,9,10]$, will be a step toward developing an efficient treatment algorithm for KA based on the tumor's size and/ or location, especially in elderly debilitated patients as well as those refusing surgery.

\section{ACKNOWLEDGEMENTS}

We thank the participants of the study.

Funding. No funding or sponsorship was received for this study or publication of this article.

Authorship. All named authors meet the International Committee of Medical Journal d Appearance of the tumor on the front prior to treatment. e Appearance of the tumor 4 weeks after starting treatment. f Appearance of the tumor 8 weeks after starting treatment (total of 8 methotrexate injections), with minimal atrophic cicatricial outcomes

Editors (ICMJE) criteria for authorship for this article, take responsibility for the integrity of the work as a whole, and have given their approval for this version to be published.

Disclosures. Massimiliano Scalvenzi, Angela Patrì, Claudia Costa, Matteo Megna, Maddalena Napolitano, Gabriella Fabbrocini, and Nicola Balato have nothing to disclose.

Compliance with Ethics Guidelines. Informed consent was obtained from all individual participants for being included in the study.

Open Access. This article is distributed under the terms of the Creative Commons Attribution-NonCommercial 4.0 International License (http://creativecommons.org/licenses/ by-nc/4.0/), which permits any noncommercial use, distribution, and reproduction in any medium, provided you give appropriate credit to the original author(s) and the source, provide a link to the Creative Commons license, and indicate if changes were made. 


\section{REFERENCES}

1. Yoo MG, Kim IH. Intralesional methotrexate for the treatment of keratoacanthoma: retrospective study and review of the korean literature. Ann Dermatol. 2014;26:172-6.

2. Martorell-Calatayud A, Requena C, Nagore E, et al. Intralesional infusion of methotrexate as neoadjuvant therapy improves the cosmetic and functional results of surgery to treat keratoacanthoma: results of a randomized trial. Actas Dermosifiliogr. 2011;102:605-15.

3. Costa C, Scalvenzi M, Fabbrocini G, Villani A.The remarkable increase of squamous cell carcinomas: a retrospective single-center study of 14-years study period. G Ital DermatolVenereol. 2018. https://doi. org/10.23736/S0392-0488.18.06144-8.

4. Veerula VL, Ezra N, Aouthmany M, Graham TA, Wolverton SE, Somani AK. Multiple keratoacanthomas occurring in surgical margins and de novo treated with intralesional methotrexate. Cutis. 2016;98:E12-E1515.
5. Remling R, Mempel M, Schnopp N, et al. Intralesional methotrexate injection: an effective time and cost saving therapy alternative in keratoacanthomas that are difficult to treat surgically. Hautarzt. 2000;51:612-4.

6. Olsen EA. The pharmacology of methotrexate. J Am Acad Dermatol. 1991;25:306-18.

7. Stranc MF, Robertson GA. Conservative treatment of keratoacanthoma. Ann Plast Surg. 1979;2:525-30.

8. Larson PO. Keratoacanthomas treated with Mohs'micrographic surgery (chemosurgery): a review of forty-three cases. J Am Acad Dermatol. 1987;16:1040-4.

9. Kirby JS, Miller CJ. Intralesional chemotherapy for nonmelanoma skin cancer: a practical review. J Am Acad Dermatol. 2010;63:689-702.

10. Annest NM, VanBeek MJ, Arpey CJ, Whitaker DC. Intralesional methotrexate treatment for keratoacanthoma tumors: a retrospective study and review of the literature. J Am Acad Dermatol. 2007;56:989-93. 